\title{
Temporal Decentering and the Development of Temporal Concepts
}

\author{
Teresa McCormack \\ Queen's University Belfast \\ Christoph Hoerl \\ University of Warwick
}

This article reviews some recent research on the development of temporal cognition, with reference to Weist's (1989) account of the development of temporal understanding. Weist's distinction between two levels of temporal decentering is discussed, and empirical studies that may be interpreted as measuring temporal decentering are described. We argue that if temporal decentering is defined simply in terms of the coordination of the temporal locations of three events, it may fail to fully capture the properties of mature temporal understanding. Characterizing the development of mature temporal cognition may require, in addition, distinguishing between event-dependent and eventindependent thought about time. Experimental evidence relevant to such a distinction is described; these findings suggest that there may be important changes between 3 and 5 years in children's ability to think about points in time independently of the events that occur at those times.

\section{Introduction}

In 1989, Richard Weist published a paper entitled "Time concepts in language and thought: Filling the Piagetian void from two to five years," which began with the claim that there had been next to no research conducted that addressed the development of temporal cognition in the early years. As its title makes clear, Weist's work - an elaboration of an account first put forward three years earlier

\footnotetext{
This research was supported by an interdisciplinary project grant on Causal Understanding: Empirical and Theoretical Foundations for a New Approach from the Arts and Humanities Research Council, UK.

Correspondence concerning this article should be addressed to Teresa McCormack, School of Psychology, Queen's University Belfast, David Keir Building, 18-30 Malone Road, Belfast, UK BT9 5BP. Internet: t.mccormack@qub.ac.uk
} 
(Weist, 1986) - was an attempt to describe and explain how time concepts changed from the end of infancy through to the end of the fifth year. The account is fundamentally a cognitive developmental one, although Weist draws primarily on studies of children's language to support his proposals regarding a set of key developmental stages. It is fair to say that even though it is now around 20 years since the publication of Weist's work, there are very few competing accounts of the development of temporal concepts in the literature. Moreover, although Weist's account is sufficiently well articulated to be a plausible candidate to fill the "Piagetian void" that he identified, it is not widely referred to by developmental psychologists. In fact, as others have noted, it is difficult to find reference to temporal cognition anywhere in standard developmental psychology textbooks, and in this respect, time differs markedly from any other core domain (Nelson, 1996). Although there has been some Piagetian-inspired research on children's ability to reason about duration, speed, and distance (e.g., Acredelo \& Schmid, 1981; Levin, 1977, 1982), there is relatively little published research in the cognitive developmental literature on children's temporal concepts (for notable exceptions, see Friedman, 1990, 2003, 2005; Nelson, 1996; see also Moore \& Lemmon, 2001).

This gap in the cognitive developmental literature contrasts greatly with the large body of research on time in children's language - in particular, research on the acquisition of tense. Indeed, it has been suggested that "[the] acquisition of tense and aspect has probably been the most prolific topic of research in the field of applied linguistics" (Slabakova, 2002, p. 172). In fact, though, one of the most long-standing and fundamental debates within that literature namely the debate over whether children's early use of tensed forms marks aspect rather than tense (e.g., Antinucci \& Miller, 1976; Rispoli \& Bloom, 1985; Weist, Wysocka, Witkowska-Stadnik, Buczowska, \& Konieczna, 1984) can be interpreted as being, at heart, a debate about children's concepts. Put simply, the issue at the core of the debate is whether young children's use of tensed forms marks a genuine deictic relationship (i.e., whether such use is actually underpinned by something like the adult distinction among past, present, and future as different stretches of time in which an event or situation can be located). It is striking that such debates have, by and large, not fed into the mainstream cognitive developmental literature.

The aim of the current article is twofold. First, we wish to briefly summarize Weist's key claims about cognitive development, focusing particularly on the role he accords to temporal decentering. Second, we want to consider relevant research in the cognitive developmental literature that has been conducted since publication of Weist's work and to examine how it relates to the account 
offered by Weist. In doing so, we distinguish between two features of temporal cognition that may develop in the relevant period: the ability to coordinate at least three locations in time (taken as a hallmark of temporal decentering) and the ability to conceive of temporal locations independently of the events that have occurred at them.

\section{Weist on Temporal Decentering}

The earliest research conducted on temporal decentering was described by Cromer (1971). Cromer's study involved telling children a brief story of a sequence of events that was illustrated in a sequence of pictures, with the left/right direction in which the pictures were put in front of the children corresponding to the earlier/later direction in time. One sequence of pictures showed, for instance, a child climbing the ladder of a slide, then the child sliding down the slide, and then finally the child having fallen off the bottom of the slide and with a pained look on her face. Once the complete story had been illustrated, children were asked to point to the picture in which the protagonist might make certain utterances. In Cromer's terminology, a "decentered" response was required when, because of the tense of the utterance, the correct picture to point to was actually different from the picture that showed the event mentioned in the utterance. Thus, for instance, in the story involving the slide, the correct picture to point to in which the depicted child might say "I will go down the slide" is the picture showing her climbing up the ladder. What Cromer found was that it was not until the age of 4 or 5 that children could produce the correct response when a decentered response was required.

Weist seemed to share the general idea behind Cromer's study, according to which temporal decentering involves something akin to the ability to adopt a temporal perspective on an event from a point in time that may not coincide with the time of the event itself or with the present time. Weist's own account of the development of temporal decentering is inspired by Reichenbach's (1947) analysis of tense. One element of this analysis is the basic idea that the use of tense marks the relationship between the time of utterance (Speech Time, ST) and the time of the event that is being referred to (Event Time, ET). For example, in the utterance "I ate the cheese," the tense of the verb marks the fact that the eating of cheese took place at a time before the time of utterance. However, in addition to ST and ET, Reichenbach's analysis also introduces a further, third element that mediates between ST and ET, which is labeled Reference Time (RT). The notion of RT is particularly clear in cases in which it does not coincide with ST or ET (e.g., in the pluperfect/past perfect tense). 
Consider a sentence such as "I had eaten the cheese." This sentence introduces a third time that differs from both ST and ET, a time that occurred after the cheese had already been eaten (the ET) but before the current ST. This time is the RT. Similarly, a sentence in the future perfect tense such as "I will have made the bed" introduces an RT that is in the future some time after the bed has already been made. These distinctions among ST, ET, and RT have been widely recognized within the literature (although see, e.g., Klein, 1994, for alternative terminology and analysis).

On Weist's account, even early use of tense marks a deictic relationship, in that it locates the event in question "before now" or "after now" and thus demonstrates some appreciation on the part of the child of the nature of the relationships among past, present, and future. However, children's early use of tense is thought to be underpinned by an understanding of temporal relationships that is severely limited. At this stage (approximately 1 to $2 \frac{1}{2}$ years), children can only think of events as occurring before the present or subsequent to it, but they have no way of considering the temporal relationships between events from a different temporal perspective. Thus, crucially, they have no way of grasping, for example, that events that are currently taking place would have been in the future from the perspective of a point of time in the past and will be in the past from the perspective of a point of time in the future. This is the sense in which, on Weist's account, young children are incapable of temporal decentering.

As children get older, Weist argued, temporal decentering emerges in two stages, which are mirrored linguistically in what he calls the Restricted Reference Time system and the Free Reference Time system, respectively. Thus, on his account, children first start to become capable, around 2 to 3 years, of a rudimentary form of decentering in which they can use an RT that can vary between ST and ET. That is to say, there is a sense in which children at this stage can consider past and future events, not just from their own present perspective but also from the perspective of the time when those events happened. However, this kind of decentering is still restricted in that the RT must coincide with one of the temporal locations that children are already capable of considering (ST and ET). At the more advanced stage, children become capable of more flexible decentering that allows them to freely consider temporal relationships between events by using an RT that may not coincide with either ST or ET.

Weist found evidence for the emergence of the Restricted RT system in the initial use of temporal adverbs and adverbial clauses (e.g., "yesterday/tomorrow"; "when..."). He argued that the early use of such adverbs introduces a specific temporal context with respect to which events happening 
within that context are then referred to, even though the context cannot yet be easily separated from the events themselves. One way to express this is to say that a child saying "yesterday I made a cake" is not just indicating that the cake-making happened "before now," but is at least attempting to introduce the idea of a particular other time at which it happened, even though the word "yesterday" may not be used with its precise meaning (i.e., as indicating the day immediately preceeding the one on which the utterance is made). Evidence for the more advanced Free RT system is thought to be present when children start making flexible use of temporal prepositions (e.g., "before" and "after") and of certain tensed forms such as the pluperfect ("I had made the cake"). Such linguistic forms seem to clearly introduce an RT that does not coincide with ST or ET.

\section{The Idea of Two Stages in the Development of Temporal Decentering}

Although Weist's distinction between two stages of temporal decentering is framed largely in terms of the linguistic correlates of these stages, it is important to consider whether we can further articulate the distinction in terms of stages of cognitive development. Elsewhere, we have argued that one way of thinking about stages of temporal decentering is in terms of a distinction between perspective switching and perspective taking (McCormack \& Hoerl, 1999). The idea is that the very young child may be capable of simply switching between perspectives (e.g., from the present to the past) without having a proper grasp of the nature of the relationship that holds between those perspectives. In contrast, a child capable of true temporal perspective-taking grasps the objective temporal relationships that exist between different temporal perspectives. We can try to make the distinction between perspective switching and perspective taking clearer by drawing a parallel with a distinction made in the literature on pretence.

Pretend play involving object substitution occurs from around 18 months onward and is often discussed as evidence that children's thinking is beginning to become "freed-up" from a preexisting dependence on how things actually are in the world (Harris, 2000; Harris \& Kavanaugh, 1993; Woolley, 2002). In pretend play, children seem to be able to switch between different ways of thinking about the same object (e.g., switch from treating a banana as a banana to treating it as a telephone, to use Leslie's [1987, 1988] well-known example). However, early pretence may involve perspective-switching without the child actually being able to conceive of the relationship between the real 
and the pretend identity of the object - that is, without, for instance, being able to represent "I am pretending of the banana that "this is a telephone", (Harris, 1991; Jarrold, Carruthers, Smith, \& Boucher, 1994; Smith, 2002). Thus, although pretend play demonstrates that the child can switch between two difference stances regarding the object, the child may not actually grasp the relationship between these difference stances and may realise that they can represent a single object in two ways (Lillard, 1993; Perner, 1991). It may be several years later until children actually understand, for example, the mentalistic nature of pretence (Lillard, 1993, 1994; Rosen, Schwebel, \& Singer, 1997). In fact, there is considerable debate within the literature on pretence as to its representational requirements; see Mitchell (2002).

The general point of bringing in an analogy with pretence is not to argue that early in development, children treat past events as in some sense "unreal." Rather, it is to draw out the distinction between more primitive perspectiveswitching and true perspective-taking. Thus, analogously to the case of early pretence, the earliest form of temporal decentering may merely involve the child mentally switching to a different temporal context without actually fully representing or understanding the temporal relationships that the different context has with other points in time. In contrast, full-blown temporal decentering involves a grasp of the systematic relationships that obtain between different temporal perspectives in virtue of the fact that they are all different perspectives on the same chronology of events. We elaborate on what this may demand in the next sections.

For the moment, it may be worth mentioning a further issue with regard to the two-stage model of temporal decentering: Is there a difference between the two stages not just in the extent to which they involve different degrees of competence in considering temporal relationships but also in the extent to which they are under the child's voluntary control? The idea is that early perspective-switching may be largely either facilitated by adults or triggered relatively automatically by environmental cues, rather than as a result of the child spontaneously starting to think back to the past or deliberate about the future. Certainly, the literature on the development of autobiographical memory has emphasized a developmental shift from talk about the past that relies heavily on adult scaffolding to one that is initiated and structured by the child (Fivush, 1994; Fivush \& Hamond, 1990; Nelson, 1993, 1996, 2001; Nelson \& Fivush, 2004). Furthermore, Hudson $(2002,2006)$ has suggested that talk about the future is initially scaffolded by adults in a similar way. Indeed, both in the case of talk about the past and in the case of talk about the future, it has been claimed that individual differences in memory development and in future thinking may 
be related to the characteristics of parental scaffolding (Fivush, Haden, \& Reese, 2006; Hudson, 2002, 2006; Reese, 2002; Reese \& Newcombe, 2007).

\section{Measuring Temporal Decentering}

Attempts to measure temporal decentering such as Cromer's (1971) rely heavily on linguistic paradigms (see also Harner, 1980). In fact, it is extremely difficult to devise paradigms assessing children's temporal cognition that do not draw heavily on language, which is a possible reason why there are few widely recognized paradigms in the cognitive developmental literature. Are there any other tasks that appear to require temporal decentering as Weist has characterized it? One feature of his characterization is the requirement, as demonstrated by language use involving a separate ST, ET, and RT, that children can coordinate three separate temporal locations. In a recent series of studies (McColgan \& McCormack, in press), we have attempted to examine whether 3-5-year-olds can reason flexibly about novel past and future event series in a task that requires considering how at least three locations in time are related to each other (the present, and at least two locations in time in either the past or the future). In that sense, the demands of our task echo Weist's requirements for the Free RT system. One important aim of our studies was to examine whether reasoning about the past and the future emerge in parallel (see Busby \& Suddendorf, 2005; Suddendorf \& Busby, 2005) an issue also touched on in the linguistics literature (Harner, 1982).

In both the past and future tasks used in our studies, children were shown a toy zoo with five cages arranged in a semicircle, with a semicircular path that passed each animal. In the central cage, there was a kangaroo. Beside the other cages, but not beside the kangaroo's cage, there were boxes that were described to children as lockers. In the past task, children were introduced to a doll that had a rucksack on her back that contained a Polaroid camera. As she visited each animal in turn, the doll placed the bag in the locker beside the animal's cage. At the kangaroo's cage, there was no locker. At that point, the doll removed the camera from the bag and took a Polaroid photograph of the kangaroo, which remained in view of the child for the rest of the procedure. She then put the camera back in her bag and continued around the zoo visiting the last two animals and putting her bag in the locker beside each in turn. At test, children were shown that the camera was missing from the bag and told that it must have fallen out into one of the lockers. They were then asked to choose one of the lockers to search in; the correct response was to search in one of the two locations visited after the kangaroo (locations 4 and 5). 
Answering correctly involved thinking back to when the camera had last been used and then considering the whole temporal sequence of events that had just unfolded in order to identify the possible points in the sequence at which the camera could have been lost.

In the future task, the layout was the same, but the children were introduced to a doll that had a camera but no rucksack. They were told that she wished to take a picture of the kangaroo but needed to leave the camera in a locker so she could pick it up on her way to visit the kangaroo. Children were asked to indicate where she should leave the camera. The correct response was to choose either of the two locations that the doll would visit before the kangaroo (locations 1 and 2). Answering correctly involved thinking about a point in the event sequence at which the camera would be needed and then identifying an occasion prior to that point at which the camera could be picked up.

Three-, four-, and five-year-olds were tested on both types of task. The only age group that performed consistently above chance was the 5-year-old group. Four-year-olds' problems on the future task were robust and remained even when they were cued to think about the temporal order in which the doll would visit the animals and when the task was simplified so that there was only one animal location before and one animal location after the kangaroo. However, simplifying the task did allow 4-year-olds to perform successfully on the past task.

Our results suggest that there are important changes between 3 and 5 years in the ability to reason flexibly about sequences of novel events in the past and future. They also suggest that, at least under some circumstances, 4-year-olds might find it easier to think about the past than about future, hypothetical, event sequences, a finding that is reminiscent of those of Harner (1980) and Cromer (1971). The tasks do have a spatial component, but it is difficult to devise tasks that do not involve translating temporal order into spatial order in an attempt to make it explicit to children. Previous research indicated that preschool children can translate spatial sequences into temporal ones (e.g., Das Gupta \& Bryant, 1989; Fivush \& Mandler, 1985; Friedman, 1977; Friedman \& Kemp, 1998). Furthermore, it seems likely that the fact that temporal order is mirrored in the spatial layout should facilitate rather than hinder performance, particularly because the layout is extremely simple.

Whether these tasks should be considered as tasks measuring temporal decentering in the sense intended by Weist (1989) is another matter. The tasks require children to think about the relationships between events happening at different times (i.e., the camera must have been lost after it had been used to take the photograph, and the doll must pick up the camera before she reaches the 
kangaroo). However, the experimenter never uses the terms "before" and "after" during the task, and it would be interesting to examine whether performance on the tasks relates to performance on tasks that actually require children to indicate their comprehension of the terms "before" and "after," such as those of Trosborg (1982). It may also be interesting to examine the relationship between performance on our task and the production and comprehension tasks used by Weist and colleagues that assess young children's capacity to understand referential location in time (see Weist, Lyytinen, Wysocka, \& Atanassova, 1997). As we have said though, it is a matter for debate whether our task should be considered to be one that measures temporal decentering in the sense intended by Weist. Unfortunately, the absence of well-established paradigms for measuring this ability makes it difficult to decide this issue empirically. We now turn to consider whether there is a further feature of mature temporal thought that this discussion of McColgan and McCormack's (in press) study has perhaps not brought out sufficiently clearly: the capacity for event-independent thought about times.

\section{Flexible Temporal Location Coordination as the "End Point" of the Development of Temporal Concepts?}

In her insightful discussion of the developmental emergence of temporal thought, Nelson (1996) argued strongly that "there is reason to doubt that the developmental course of the expression of ST-ET-RT relations is as constrained by cognitive development as Weist suggests" (p. 281). She based her argument on a consideration of the monologues produced by Emily, a young child whose presleep monologues were recorded by her parents and have since been the focus of considerable interest to researchers interested in the development of language and narrative abilities (see Nelson, 1996). Nelson's argument is that if sections of narrative are considered as a whole rather than dissected into individual sentences, Emily appears to be able to introduce RT and coordinate it with not just one but a number of different ETs before she is even two years old. One possible interpretation of Nelson's (1996) point here is that analysis of individual sentences rather than the connected discourse of a narrative has led to an underestimation of the age at which children start to use a Free RT system. Thus, her argument could be read as an argument about when we should think this advanced system emerges. However, her point needs to be considered in the context of her other suggestions about the role of event knowledge in development. Nelson's (1996) general line of argument is that abstract temporal concepts must emerge from the child's experiences with repeated event 
sequences. Early in development, temporal concepts may initially only be present implicitly in children's cognitive representations of such sequences. Furthermore, she argued that children may use particular temporal terms in a limited way only within the context of certain familiar event sequences or routines (see, e.g., Emily's formulaic use of "today" and "afternoon," a use that is not, at least initially, underpinned by a genuine comprehension of the terms' meanings).

One interesting interpretation of Nelson's (1996) position is as follows. A basic form of decentering is indeed manifest in Emily's coordination of ST, ET, and RT across a section of narrative, but she can only coordinate temporal relationships within the context of single, usually familiar event sequences. In particular, she has no way of thinking about the temporal relationships among a number of such sequences. Gerhardt (1989) has put the point as follows: "[T]here is no evidence that she can yet interrelate different event frames or freely interpolate events within these frames" (p. 204). We can distinguish two related ideas implicit in this line of thought: First, Emily may have no unitary way of representing the temporal relationships between events belonging to all sorts of different event sequences; secondly, she may have no way to think about time at all, other than in terms of the events that occupy it and the familiar types of sequences in which they follow each other. It is in this sense that we might say that young children's understanding of time is "event-based" (McCormack \& Hoerl, 1999).

We can contrast this with our adult mature concept of time, which allows us to think about a unitary system of temporal locations in a way that is, in an important sense, independent of the events that occur in it. Indeed, our conventional clock and calendar system gives us a very precise way of singling out and referring to any point in time without reference to an event that may have or will occur at that point in time. For example, $11 \mathrm{Am}$ may be the time at which we had coffee today, but the conventional clock system allows us to refer to that time without reference to what happened at that time today or what usually happens at that time. A parallel can be made here with the way we think about space: In our mature way of thinking about space, we can easily distinguish between particular spatial locations and the objects that occupy those locations. Although our way of identifying particular locations may depend, for example, on the ability to refer to objects actually in, or standing in some other spatial relationship to, those locations (cf. e.g., Strawson, 1959), once we have a fix on the location, we can readily conceive of that location independently of those objects; for example, we can think of the place where our car is parked as a space that might also be empty or where someone else's car might be parked. 
A crucial difference between the spatial and the temporal case is that it may be more difficult for children to learn to conceive of time as event independent than it is for them to learn to conceive of space as object independent. For example, an adult can refer to an empty spatial location (e.g., by saying "put the chair there") and indicate the specific spatial location they have in mind in a way that makes it visually obvious, whereas it is much harder to make verbal reference to a specific point in time without referring to certain events that have occurred or will occur at that time. Of course, the conventional clock and calendar system allows such event-independent reference, but the developmental period under consideration precedes children's competence with that system (Friedman, 1982, 1989, 1990), and it is tempting to assume that children can only make sense of the system if they already have the necessary way of thinking about time.

We do not wish to dwell here on issues concerning the development of spatial versus temporal concepts (see e.g., Friedman \& Brudos, 1988). The general point is that there is an aspect of our mature concept of time that goes beyond the basic notion of temporal decentering as described in terms of the coordination of different points in time. On Nelson's account, development is to a large extent a matter of thought about time becoming "freed up" from thought about familiar sequences of events. Her considerations suggest that linguistic evidence of coordinating a number of points in time (ST, ET, and RT) falls short of demonstrating a mature concept of time precisely because such coordination may still be underpinned by an event-based notion of time (see Campbell, 2006, for a related argument). When children have only an event-based understanding of time, they might indeed be able to coordinate temporal relationships within individual event sequences, but they have no unitary temporal framework that allows them to consider the temporal locations of events independently of those events themselves.

The idea that development involves children's thought about time becoming independent from the events that occur within it is not a new one (and Nelson's [1996] seminal work on children's representations of event sequences provides a rich context for exploring such a notion). Although Piagetian work on time has largely focused on children's grasp of the relationships among time, speed, and distance, his basic claim was that children's early notion of time was closely tied to observable properties of objects or events. Demonstrations that young children conflate temporal duration with, for example, distance traveled (Piaget, 1969; see Wilkening, 1982) or amount of activity (Arlin, 1986) were originally interpreted within the Piagetian framework as evidence that young children cannot abstract time from other event dimensions. The notion of a shift from 
event-dependent to event-independent thought about time also appears to be a central one within the linguistics literature. The aspect-before-tense debate is largely a debate about whether children's early use of tensed forms marks properties of events (such as, e.g., completion) rather than the deictic relationship of tense. Although it is not clear that the linguistic evidence supports strong versions of this claim, our understanding of the more recent literature is that children do find it easier to understand some types of tensed verbs (i.e., those describing certain sorts of events) than others; as Wagner (2001) put it, there are aspectual influences on tense comprehension. Furthermore, there is some evidence that the earliest uses of past tense forms are more likely to occur in certain event contexts and for certain types of verbs than others (Shirai \& Miyata, 2006). In other words, the basic intuition behind the aspect-before-tense hypothesis - that children's understanding of time is closely tied to their representations of events - may be correct, even if a strong version of the hypothesis is not. Indeed, although Weist (1989) argued against the aspect-before-tense hypothesis, one way of interpreting the cognitive underpinning of his distinction between the Restricted and Free RT systems is that at the Restricted stage, children's use of RT is dependent on knowledge about particular events that happened or will happen at that time (inasfar as they can separate RT from ST at all). Furthermore, Weist $(1986,1989)$ has argued that young children's mastery of the terms "before" and "after" is limited in a sense that suggests a difficulty separating times of events' occurrence from the events themselves. In particular, they have difficulty in understanding these terms when the order of mention of occurrence of events is the reverse of the order of actual occurrence (Trosborg, 1982).

\section{From Event-Based to Event-Independent Understanding of Time}

We have suggested that children's grasp of time and of temporal order relationships is initially tied to their knowledge of familiar event sequences. To get a better understanding of the kind of limitation at issue here, it might help to consider some recent empirical research that might also be interpreted as suggesting that there is a developmental shift from an event-based to an event-independent understanding of time.

It is a feature of the adult concepts "before" and "after" that they can be applied to arbitrary pairs of events. For example, we can easily make sense of the question as to whether one past event occurred before or after another one, even if the events in question were entirely unrelated and occurred at widely spaced intervals. If young children's understanding of time is indeed event 
based in the way we have suggested, they cannot be said to have a full grasp of those concepts. Yet, an empirical challenge to this idea might be thought to come from research carried out by William Friedman, who has examined a wide variety of aspects of children's temporal cognition. In one study with 4-yearolds (Friedman, 1991), children were asked to judge the relative recency of two novel events that had happened in a school-based setting. The two events were "one-off" events that were not related to each other, such as a demonstration of tooth-brushing technique using an oversized toothbrush or a visitor making a video of the class. One of the events took place 7 weeks before the test and the other took place 1 week before the test. What Friedman found was that even 4-year-olds were above chance in answering the question as to which of the two had happened a long time ago and which happened a short time ago.

Along with other studies, including ones involving adults (Friedman \& Huttenlocher, 1997), this study provides strong evidence for what Friedman calls "distance-based" processes, which can at least sometimes inform temporal judgments (see Friedman, 1993). The children who passed Friedman's task were at chance when asked about the day of the week or month in which each of the events had happened, suggesting that their responses were not made on the basis of locating the two events in a conventional time pattern (e.g., on the basis of knowledge that one event happened in February and another in April). Instead, they seemed to rely on some sort of direct impression of distance from the present of the events in question.

Friedman's (1991) results may be thought to suggest that, at least by 4 years, children have some basic notion of distance in time that allows them to think about the relative recency (i.e., distance from the present) of any pairs of events, even unrelated ones widely separated in time. It is not obvious, though, that this equates to an understanding of the temporal relationship between those two events in terms of something like the adult concepts of "before" and "after." In particular, it is unclear whether successful performance on Friedman's task requires a grasp of a linear order leading up to the present along which past events are arranged (McCormack \& Hoerl, 2001). Consider again a spatial analogy. A child might know, of two separate places that are visited on a regular basis, that one is further away than the other, without this implying that the child has a proper grasp of how these two places are related to one another. Because of the linear structure of time, it is, of course, in principle possible to derive information about the relation between two past events from information about their respective distances from the present, in a way for which there is no analogue in the spatial case. The question here, though, is what a grasp of time as linear comes to, and whether children do in fact have such a grasp. There 
is also some evidence from other work of Friedman's (2000) that children are prone to confuse the near future with the recent past in their judgments about the distance of events from the present. Thus, using distance-based processes to arrive at judgments about the relative recency of two events may actually be compatible with a very limited understanding of the structure of time.

One important aspect of a mature understanding of before/after relationships is a grasp of the fact that when two events have happened, it can often make a difference to the overall result which of the two events happened before the other. Indeed, it can be argued that this type of understanding is crucial for grasp of time as linear (Martin, 2001; McCormack \& Hoerl, 2005). One study that has examined the development of this sort of understanding is reported by Povinelli, Landry, Theall, Clark, and Castille (1999). The study involved children sitting at a table facing an experimenter, who played first one game and then a second game with the child. Located behind the child were two different boxes and a second experimenter, who put a puppet into one of the two boxes during game 1 and then moved the puppet to the other box during game 2. A video camera was set up to capture, from over the shoulder of the first experimenter, the child playing the two games and, behind the child, the second experimenter hiding the puppet. After the two games had finished, the child was invited to watch the video-recording, now seeing for the first time the second experimenter hiding the puppet in the two boxes. The crucial manipulation was that children were shown two separate video clips of the two games they had played, and they were not always shown the two video-clips in the order in which they had played the games. After they had watched the two video-clips, the children were then asked which box they thought the puppet was in now. Three-year olds were at chance in answering this question; 5-year olds could make the appropriate inference, although they needed to be reminded about the order in which the games were played.

In their study, Povinelli et al. (1999) sought to make sure that children did remember which of the two games they had actually played more recently; that is, unlike in Friedman's study, their interest was not in assessing whether children could make relative recency judgments about the two game-playing events. Rather, they were concerned with whether children can put such relative recency information to work in their reasoning about how the world is right now. As they put it, their interest was in whether children understood "that the events from their recent past are part of a causal arrow of time- a flow of events leading up to and causally determining the present" (Povinelli et al., 1999, p. 1433). Arguably, what Povinelli et al.'s task also brings out, though, is that this sort of understanding requires what we have referred to as an 
event-independent understanding of time, at least in the following sense. To pass the task, children need to grasp that their memory of which of the two games they played more recently gives them information about the relative order of two different points in time that they can also use in determining which of the two puppet-hiding events was the more recent one. In other words, the task involves not just the ability to get right the order in which the two games were played but also a grasp of the fact that when each of the two games was played, it coincided with another event (the puppet-hiding events). Thus, the task seems to require the general idea of points in time at which events of different types can coincide with one another.

Of course, in Povinelli et al.'s (1999) task, children must also realize that the information they are being provided with in the videos can be used to find out which puppet-hiding event coincided with which game. Although Povinelli et al. argued that children of the relevant age do not have a general problem with using information provided by a videotape, ideally their findings would be extended to a context in which this representational medium was not employed. That children seem to have difficulties with thinking about times independently of the events that happen at those times is perhaps demonstrated even more clearly in two experiments we have carried out, which were originally inspired by Povinelli et al.'s study. These studies involved events that children could not perceive at the time of their occurrence, but they did not involve showing videotape footage.

In one of the studies (McCormack \& Hoerl, 2005), children were initially introduced to two dolls, Sally and Katy, who always performed actions in a certain order: They learned that Sally always went first and then Katy always went next. Children were also shown a novel piece of apparatus - a large yellow box with two differently colored buttons - and learned how it worked. Pressing one of the buttons caused a toy car to drop down one chute and appear on a shelf in a transparent window, whereas pressing the other button caused a marble to drop down another chute and appear on the shelf. The box was mechanically constructed such that whatever toy was already in the window dropped out of sight into a drawer below before a new toy appeared, so that there was only ever one toy left in the window, and which toy that was depended on which button had been pressed last. Children were given the opportunity to learn which button yielded which toy. At test, a screen was then put in front of the box and, out of view of the child, Sally and Katy pressed one button each. Finally, the box was uncovered again. In one version of the task, after the screen was removed, children could see each doll standing next to the button that she had pressed, but the window in the box was left occluded. In this version, which 
4-year-olds consistently failed, children had to infer which toy was inside the window.

The other study (McCormack \& Hoerl, 2007) also involved two doll characters, John and Peter, and a doll's house with a bathroom that had a door that could be closed, so that children could not look inside it; the experimenter still had access to the bathroom through the back of the doll's house. The children were told that the dolls were going to go into the bathroom to brush their hair, which had got messy when they were playing outside. The hairbrush, which was sitting by the bathroom sink, was pointed out to them, as were two differently colored cupboards. When the two dolls went into the bathroom, the experimenter closed the door and then said "You can't see John right now, but he goes first and gets the hairbrush and now he is brushing his hair. Now he puts the hairbrush in one of the cupboards. Peter goes last. You can't see him now, but he gets the hairbrush out and now he is brushing his hair. Now he puts the hairbrush into the other cupboard." After this, the bathroom door was opened to reveal each of the dolls standing beside one of the cupboards. Participants were then told that each doll was standing beside the cupboard that he had placed the hairbrush in and were asked two control questions to confirm that they could remember the order in which the two dolls had brushed their hair, followed by the test question "So, where do you think the brush is right now?" Four-year-olds performed at chance in this task, although 5-year-olds were successful.

One way of thinking of both of these tasks, which might explain the nature of the difficulty children had with it, is as follows. To answer the question as to which toy is in the window or which cupboard the hairbrush is in, the children have to bring together information about the order in which the dolls had acted with information, supplied at a later time, about the particular action each of the dolls had carried out. Arguably, though, bringing together these two pieces of information requires operating with a notion such as "the time when Katy pressed the button," which they can then subsequently also think of "the time when the blue button was pressed," in order to arrive at the conclusion that the blue button was pressed after the red one. What is required here is the ability to think, not just in terms of event types, which typically happen before or after certain other event types (as in a familiar sequence), but in terms of a sequence of points in time, about which more and more information is revealed as the experiment progresses, so that a point in time at which a particular event of a certain type has happened can later also be identified as the point in time at which a particular event of some different type has happened. 
Put this way, one distinctive feature of event-independent thought about times is that it involves a way of thinking about points in time that leaves open, at least to some extent, which events happened at those points in time. Yet, it might be thought that event-independent thought about time in this sense can actually already be found in children's representations of familiar event sequences of the type studied by Nelson, which are often referred to as scripts (Nelson, 1986; Schank \& Abelson, 1977). In the literature on children's grasp of scripts, it is typically assumed that scripts can include optional elements. A child's script for going to a fast-food restaurant, for instance, may leave open which drink the child chooses. Thus, there is a sense in which scripts may include placeholders that can be filled in different ways on different occasions when the sequence of activities described by the script is carried out. There are good reasons, though, for thinking that operating with such placeholders within a script falls short of a genuine appreciation of different possibilities and that we can therefore distinguish between this sort of case and one in which what we have called event-independent thinking about time is present.

A perhaps unexpectedly relevant set of results here comes from recent research on children's ability to make counterfactual and hypothetical judgments. There is a considerable body of research that suggests that 3-4-year-olds can give the correct answer to questions about what might have happened if things had unfolded in a different way than they actually did (e.g., German \& Nichols, 2003; Harris, German, \& Mills, 1996; Perner, Sprung, \& Steinkogler, 2004). However, it is not clear that such counterfactual judgments are always underpinned by the adult notion that what has happened is only one outcome from a number of past possibilities or that what will happen is also only one outcome from a number of future possibilities. Beck, Robinson, Carroll, and Apperly (2006) attempted to examine this issue by asking children what they call "open" counterfactual questions. Their experimental apparatus involved a vertical tube that branched in two in the middle. In one study, a ball was dropped down the apparatus and, on any given trial, could emerge from either branch. Once the ball had emerged, children were either asked "What if it had gone the other way, where would it be?" (the authors called this the "standard counterfactual question") or "Could it have gone anywhere else?" (the "open counterfactual question"). A 3-4-year-old group found the standard counterfactual question much easier to answer than the open counterfactual question. Additional experiments allowed children the opportunity to demonstrate their understanding that, on any given trial, an object could travel down either one of two tubes by placing a mat under each tube to catch a falling object. Again, young children's responses 
demonstrated they had difficulty grasping that there was more than one possible outcome.

In order to explain the particular difficulty children have with the open counterfactual question, Beck et al. (2006, p. 420) suggested that they may actually be able to answer the standard counterfactual question correctly "without necessarily thinking in terms of alternative possibilities." The first half of the question may simply tell them to imagine a certain scenario, and the second half then ask them to provide further information about a feature of that imagined scenario. All this they may be able to do without taking into consideration what actually happened. In contrast, answering the open counterfactual question does seem to require considering thinking back to an earlier time and recognizing that although events unfolded a certain way at that time, there was a possibility that they could have unfolded some other way.

Beck et al. (2006, p. 423), who also presented similar findings from studies involving future hypotheticals, concluded that "we have no evidence to support the proposal that when 3- and 4-year-olds answer counterfactual and future hypothetical questions they are treating them as possibilities." This conclusion is provocative because it suggests that children's thinking about the past and future may be "event based" in a very specific way: They cannot conceive of a point in time as a point at which an event actually happened, but might also not have happened, and at which a different event might have happened instead. In other words, they do not operate with a notion of points in time which would allow them to think backward or forward in time to the point in time at which certain events have happened or will happen and then to think of that point in time as one at which other events might have happened. Inasfar as they can imagine alternative scenarios to the actual world, they do not consider them as ways the world might actually have been at a particular point in time. Thus, Beck et al.'s study provides further confirmation of a developmental change from an event-based to an event-independent thinking about time.

\section{Temporal Cognition and "Mental Time Travel"}

Our opening remarks regarding the dearth of work on temporal cognition in recent developmental psychology may have seemed surprising to readers familiar with recent publications on the development of "mental time travel" in children (e.g., Atance \& O’Neil, 2005; Suddendorf \& Busby, 2005). This topic has become the focus of much attention in developmental psychology, 
spurred on to some extent by debates in comparative psychology as to whether animals are capable of mental time travel or whether this is a uniquely human achievement (Clayton, Bussey, \& Dickinson, 2003; Suddendorf \& Corballis, 2007; Tulving, 2005).

On the face of it, a number of issues discussed under the topic of mental time travel might seem very close to issues that we have raised in this article. For instance, mental time travel is often seen as involving an imaginative recreation of past experiences or of possible future experiences, or the ability "to mentally project [oneself] backwards in time to re-live or forwards to pre-live events" (Suddendorf \& Corballis, 2007, p. 299). Arguably, what we have described as temporal decentering also involves some form of exercise of the imagination that might be described in quite similar terms.

Yet, throughout much of the current debate about mental time travel and, for instance, its development in children, an ability for temporal cognition is often just taken for granted; that is, researchers often write as though young children can already be credited with a view of time as stretching from the past, through the present, to the future, and populated with a variety of events of which they know the "what, where and when" (Suddendorf \& Corballis, 2007). Instead, they focus on what they see as further abilities - such as metarepresentational abilities (Perner, 2001), a certain kind of self-consciousness (Tulving, 2001, 2005), or the ability to set aside present desires in planning for the future (Atance \& Meltzoff, 2005, 2006) which might be required to "travel" in imagination forward and backward in time.

\section{Conclusion}

In our view, one key insight of Weist's work, and of some of the other researchers we have mentioned in this article, is that the very ability to think about events in time, far from being easily explained in terms of a basic ability to record "what, where, and when" information about events, is a sophisticated developmental achievement. In this article, we have concentrated on two abilities that can be seen to be involved in such development. The first ability, highlighted by Weist, is temporal decentering. However, we have argued that if this is understood just as the ability to coordinate several different locations in time, then the notion of temporal decentering in itself falls short of a description of mature temporal cognition. Specifically, we have discussed whether a richer notion of a developmental shift from an event-dependent to an event-independent concept of time is necessary to capture important changes in the first 5 years of life. 
Indeed, Weist's own characterization of the difference between the Restricted and the Free RT system, which involves the idea of children becoming able to consider events using an RT that is separate from both ST and ET, can be seen as implicitly drawing upon this idea.

\section{References}

Acredelo, C., \& Schmid, J. (1981). The understanding of relative speeds, distances, and durations of movement. Developmental Psychology, 17, 490-493.

Antinucci, F., \& Miller, R. (1976). How children talk about what happened. Journal of Child Language, 3, 167-189.

Arlin, M. (1986). The effects of quantity and depth of processing on children's time perception. Journal of Experimental Child Psychology, 42, 84-98.

Atance, C. M., \& Meltzoff, A. N. (2005). My future self: Young children's ability to anticipate and explain future states. Cognitive Development, 20, 341-361.

Atance, C. M., \& Meltzoff, A. N. (2006) Preschoolers' current desires warp their choices for the future. Psychological Science, 17, 583-587.

Atance, C. M., \& O’Neill, D. K. (2005). Preschoolers' talk about future situations. First Language, 25, 5-18.

Beck, S. R., Robinson, E. J., Carroll, D. J., \& Apperly, I. A. (2006). Children's thinking about counterfactuals and future hypotheticals as possibilities. Child Development, 77, 413-426.

Busby, J., \& Suddendorf, T. (2005). Recalling yesterday and predicting tomorrow. Cognitive Development, 20, 362-372.

Campbell, J. (2006). Ordinary thinking about time. In F. Stadler \& M. Stöltzner (Eds.), Time and history: Proceedings of the 28th International Wittgenstein Symposium, Kirchberg am Wechsel, Austria 2005 (pp. 1-12). Frankfurt: Ontos Verlag.

Clayton, N. S., Bussey, T. J., \& Dickinson, A. (2003). Can animals recall the past and plan for the future? Nature Reviews Neuroscience, 4, 685-691.

Cromer, R. F. (1971). The development of the ability to decenter in time. British Journal of Psychology, 62, 353-365.

Das Gupta, P., \& Bryant, P. E. (1989). Young children's causal inferences. Child Development, 60, 1138-1146.

Fivush, R. (1994). Constructing narrative, emotion and gender in parent-child conversations about the past. In U. Neisser \& R. Fivush (Eds.), The remembering self: Construction and accuracy of the life narrative (pp. 136-157). Cambridge: Cambridge University Press.

Fivush, R., Haden, C. A., \& Reese, E. (2006). Elaborating on elaborations: The role of maternal reminiscing style in cognitive and socioemotional development. Child Development, 77, 1568-1588.

Fivush, R., \& Hamond, N. R. (1990). Autobiographical memory across the preschool years: Toward reconceptualizing childhood amnesia. In R. Fivush \& J. A. Hudson 
(Eds.), Knowing and remembering in young children (pp. 223-248). Cambridge: Cambridge University Press.

Fivush, R., \& Mandler, J. M. (1985). Developmental changes in the understanding of temporal sequence. Child Development, 56, 1437-1446.

Friedman, W. J. (1977). The development of children's understanding of cyclic aspects of time. Child Development, 48, 1593-1599.

Friedman, W. J. (1982). Conventional time concepts and children's structuring of time. In W. J. Friedman (Ed.), The developmental psychology of time (pp. 171-208). New York: Academic Press.

Friedman, W. J. (1989). The representation of temporal structure in children, adolescents and adults. In I. Levin \& D. Zakay (Eds.), Time and human cognition: A life-span perspective (pp. 259-304). Amsterdam: North-Holland.

Friedman, W. J. (1990). About time: Inventing the fourth dimension. Cambridge, MA: MIT Press.

Friedman, W. J. (1991). The development of children's memory for the time of past events. Child Development, 62, 139-155.

Friedman, W. J. (1993). Memory for the time of past events. Psychological Bulletin, $113,44-66$.

Friedman, W. J. (2000). The development of children's knowledge of the times of future events. Child Development, 7I, 913-932.

Friedman, W. J. (2003). The development of children's understanding of the past and the future. Advances in Child Development and Behavior, 31, 229-269.

Friedman, W. J. (2005). Developmental and cognitive perspectives on humans' sense of the times of past and future events. Learning and Motivation, 36, $145-158$.

Friedman, W. J., \& Brudos, S. L. (1988). On routines and routines: The early development of spatial and temporal representations. Cognitive Development, 3, 167-182.

Friedman, W. J., \& Huttenlocher, J. (1997). Memory for the time of "60 Minutes" stories and news events. Journal of Experimental Psychology: Learning, Memory, and Cognition, 23, 1-10.

Friedman, W. J., \& Kemp, S. (1998). The effects of elapsed time and retrieval on young children's judgments of the temporal distances of past events. Cognitive Development, 13, 335-367.

Gerhardt, J. (1989). Monologue as a speech genre. In K. Nelson (Ed.), Narratives from the crib (pp. 171-230). Cambridge, MA: Harvard University Press.

German, T. P., \& Nichols, S. (2003). Children's counterfactual inferences about long and short causal chains. Developmental Science, 6, 514-523.

Harner, L. (1980). Comprehension of past and future reference revisited. Journal of Experimental Child Psychology, 29, 170-182.

Harner, L. (1982). Talking about the past and the future. In W. J. Friedman (Ed.), The developmental psychology of time (pp. 141-170). New York: Academic Press. 
Harris, P. L. (1991). The work of the imagination. In A. Whiten (Ed.), Natural theories of mind: Evolution, development, and simulation of everyday mindreading (pp. 283-304). Oxford: Basil Blackwell.

Harris, P. L. (2000). The work of the imagination. Oxford: Blackwell.

Harris, P. L., German, T. P., \& Mills, P. (1996). Children's use of counterfactual thinking in causal reasoning. Cognition, 61, 233-259.

Harris, P. L., \& Kavanaugh, R. D. (1993). Young children's understanding of pretense. Monographs of the Society for Research in Child Development, 58, Serial No. 231, i-107.

Hudson, J. A. (2002). "Do you know what we're going to do this summer?" Mothers' talk to young children about future events. Journal of Cognition and Development, 3, 49-71.

Hudson, J. A. (2006). The development of future time concepts through mother-child conversation. Merrill-Palmer Quarterly, 52, 70-95.

Jarrold, C., Carruthers, P., Smith, P. K., \& Boucher, J. (1994). Pretend play: Is it metarepresentational? Mind and Language, 9, 445- 468.

Klein, W. (1994). Time in language. London: Routledge.

Leslie, A. M. (1987). Pretense and representation: The origins of "theory of mind." Psychological Review, 94, 412-426.

Leslie, A. M. (1988). Some implications of pretense for mechanisms underlying the child's theory of mind. In J. W. Astington, P. L. Harris, \& D. R. Olson (Eds.), Developing theories of mind (pp.19-46). Cambridge: Cambridge University Press.

Levin, I. (1977). The development of time concepts in children: Reasoning about duration. Child Development, 48, 435-444.

Levin, I. (1982). The nature and development of time concepts in children: The effects of interfering cues. In W. J. Friedman (Ed.), The developmental psychology of time (pp. 47-85). New York: Academic Press.

Lillard, A. S. (1993). Pretend play skills and the child's theory of mind. Child Development, 64, 348-371.

Lillard, A. S. (1994). Making sense of pretence. In C. Lewis \& P. Mitchell (Eds.), Children's early understanding of mind: Origins and development (pp. 211-234). Hillsdale, NJ: Lawrence Erlbaum.

Martin, M. G. F. (2001). Episodic recall as retained acquaintance. In C. Hoerl \& T. McCormack (Eds.), Time and memory: Issues in philosophy and psychology. Oxford: Clarendon Press.

McColgan, K., \& McCormack, T. (in press). Searching and planning: Young children's reasoning about past and future event sequences. Child Development.

McCormack, T., \& Hoerl, C. (1999). Memory and temporal perspective: The role of temporal frameworks in memory development. Developmental Review, 19, 154-182.

McCormack, T., \& Hoerl, C. (2001). The child in time: Temporal concepts and self-consciousness in the development of episodic memory. In C. Moore \& K. 
Lemmon (Eds.), The self in time: Developmental perspectives (pp. 203-227).

Mahwah, NJ: Lawrence Erlbaum.

McCormack, T., \& Hoerl, C. (2005). Children's reasoning about the causal significance of the temporal order of events. Developmental Psychology, 41, 54-63.

McCormack, T., \& Hoerl, C. (2007). Young children's reasoning about the order of past events. Journal of Experimental Child Psychology, 98, 168-183.

Mitchell, R. W. (Ed.) (2002). Pretending and imagination in animals and children. Cambridge: Cambridge University Press.

Moore, C., \& Lemmon, K. (Eds.). (2001). The self in time: Developmental perspectives. Mahwah, NJ: Lawrence Erlbaum.

Nelson, K. (1986). Event knowledge: Structure and function in development. Hillsdale, NJ: Lawrence Erlbaum.

Nelson, K. (Ed.) (1989). Narratives from the crib. Cambridge, MA: Harvard University Press.

Nelson, K. (1993). The psychological and social origins of autobiographical memory. Psychological Science, 4, 7-14.

Nelson, K. (1996). Language in cognitive development: Emergence of the mediated mind. Cambridge: Cambridge University Press.

Nelson, K. (2001). Language and the self: From the "experiencing I" to the “continuing me." In C. Moore \& K. Lemmon (Eds.), The self in time: Developmental perspectives (pp. 15-34). Mahwah, NJ: Lawrence Erlbaum.

Nelson, K., \& Fivush, R. (2004). The emergence of autobiographical memory: A social cultural developmental theory. Psychological Review, III, 486-511.

Perner, J. (1991). Understanding the representational mind. Cambridge, MA: MIT Press.

Perner, J. (2001). Episodic memory: Essential distinctions and developmental implications. In C. Moore \& K. Lemmon (Eds.), The self in time: Developmental perspectives (pp. 181-202). Mahwah, NJ: Lawrence Erlbaum.

Perner, J., Sprung, M., \& Steinkogler, B. (2004). Counterfactual conditionals and false belief: A developmental dissociation. Cognitive Development, 19, 179-201.

Piaget, J. (1969). The child's concept of time. London: Routledge and Kegan Paul.

Povinelli, D. J., Landry, A. M., Theall, L. A., Clark, B. R., \& Castille, C. M. (1999). Development of young children's understanding that the recent past is causally bound to the present. Developmental Psychology, 35, 1426-1439.

Reese, E. (2002). Social factors in the development of autobiographical memory: The state of the art. Social Development, 11, 124-142.

Reese, E., \& Newcombe, R. (2007). Training mothers in elaborative reminiscing enhances children's autobiographical memory and narrative. Child Development, $78,1153-1170$.

Reichenbach, H. (1947). Elements of symbolic logic. New York: Macmillan.

Rispoli, M., \& Bloom, L. (1985). Incomplete and continuing: Theoretical issues in the acquisition of tense and aspect. Journal of Child Language, 12, 471-474. 
Rosen, C., Schwebel, D., \& Singer, J. (1997). Preschoolers' attributions of mental states in pretense. Child Development, 68, 1133-1142.

Schank, R. C., \& Abelson, R. P. (1977). Scripts, plans, goals, and understanding. Hillsdale, NJ: Lawrence Erlbaum.

Shirai, Y., \& Miyata, S. (2006). Does past tense marking indicate the acquisition of the concept of temporal displacement in children's cognitive development? First Language, 26, 45-66.

Slabakova, R. (2002). Recent research on the acquisition of aspect: An embarrassment of riches? Second Language Research, 18, 172-188.

Smith, P. K. (2002). Pretend play, metarepresentation and theory of mind. In R. W. Mitchell (Ed.), Pretending and imagination in animals and children (pp. 129-141). Cambridge: Cambridge University Press.

Strawson, P. (1959). Individuals: An essay in descriptive metaphysics. London: Methuen.

Suddendorf, T., \& Busby, J. (2005). Making decisions with the future in mind: Developmental and comparative identification of mental time travel. Learning \& Motivation, 36, 110-125.

Suddendorf, T., \& Corballis, M. C. (2007). The evolution of foresight: What is mental time travel and is it unique to humans? Behavioral and Brain Sciences, 30, 299-351.

Trosborg, A. (1982). Children's comprehension of "before" and "after" reinvestigated. Journal of Child Language, 9, 381-402.

Tulving, E. (2001). Episodic memory and common sense: How far apart? Philosophical Transactions of the Royal Society B, 356, 1505-1515.

Tulving, E. (2005). Episodic memory and autonoesis: Uniquely human? In H. S. Terrace \& J. Metcalfe (Eds.), The missing link in cognition: Origins of self-reflective consciousness (pp. 4-56). Oxford: Oxford University Press.

Wagner, L. (2001). Aspectual influences on early tense comprehension. Journal of Child Language, 28, 661-681.

Weist, R. M. (1986). Tense and aspect. In P. Fletcher \& M. Garman (Eds.), Language acquisition: Studies in first language development (2nd ed., pp. 356-374). Cambridge: Cambridge University Press.

Weist, R. M. (1989). Time concepts in language and thought: Filling the Piagetian void from two to five years. In I. Levin \& D. Zakay (Eds.), Time and human cognition: A life-span perspective (pp. 63-118). Amsterdam: Elsevier.

Weist, R. M., Lyytinen, P., Wysocka, J., \& Atanassova, M. (1997). The interaction of language and thought in children's language acquisition: A cross-linguistic study. Journal of Child Language, 24, 81-121.

Weist, R. M., Wysocka, H., Witkowska-Stadnik, K., Buczowska, E., \& Konieczna, E. (1984). The defective tense hypothesis: On the emergence of tense and aspect in child Polish. Journal of Child Language, 11, 347-374. 
Wilkening, F. (1982). Children's knowledge about time, distance, and velocity interrelations. In W. J. Friedman (Ed.), The developmental psychology of time (pp. 87-112). New York: Academic Press.

Woolley, J. D. (2002). Young children's understanding of pretense and other fictional mental states. In R. W. Mitchell (Ed.), Pretending and imagination in animals and children (pp. 115-128). Cambridge: Cambridge University Press. 